\title{
Redefining Noradrenergic Neuromodulation of Behavior: Impacts of a Modular Locus Coeruleus Architecture
}

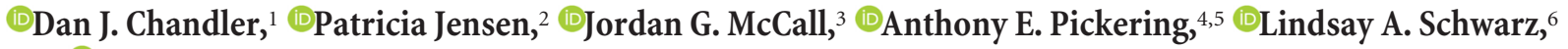 \\ and ${ }^{\odot}$ Nelson K. Totah ${ }^{7,8,9}$ \\ ${ }^{1}$ Department of Cell Biology and Neuroscience, Rowan University School of Osteopathic Medicine, Stratford, New Jersey 08084, ${ }^{2}$ Neurobiology Laboratory, \\ National Institute of Environmental Health Sciences, National Institutes of Health, Department of Health and Human Services, Research Triangle Park, \\ North Carolina 27709, ${ }^{3}$ Department of Anesthesiology, Washington University in St. Louis, St. Louis, Missouri 63110, Department of Pharmaceutical and \\ Administrative Sciences, St. Louis College of Pharmacy, St. Louis, Missouri 63110, Center for Clinical Pharmacology, St. Louis College of Pharmacy and \\ Washington University School of Medicine, St. Louis, Missouri 63110, and Washington University Pain Center, Washington University in St. Louis, St. \\ Louis, Missouri 63110, ${ }^{4}$ School of Physiology, Pharmacology and Neuroscience, University of Bristol, Bristol, BS8 1TD, United Kingdom, ${ }^{5}$ Bristol \\ Anaesthesia, Pain and Critical Care Sciences, Translational Health Sciences, Bristol Medical School, Bristol Royal Infirmary, Bristol, BS2 8HW, United \\ Kingdom, ${ }^{6}$ St. Jude Children's Research Hospital, Memphis, Tennessee 38105, ${ }^{7}$ Department of Physiology of Cognitive Processes, Max Planck Institute for \\ Biological Cybernetics, Tübingen, Germany 72076, ${ }^{8}$ Helsinki Institute of Life Science, Helsinki 00014, Finland, and ${ }^{9}$ School of Pharmacy, University of \\ Helsinki, Helsinki 00014, Finland
}

The locus coeruleus (LC) is a seemingly singular and compact neuromodulatory nucleus that is a prominent component of disparate theories of brain function due to its broad noradrenergic projections throughout the CNS. As a diffuse neuromodulatory system, noradrenaline affects learning and decision making, control of sleep and wakefulness, sensory salience including pain, and the physiology of correlated forebrain activity (ensembles and networks) and brain hemodynamic responses. However, our understanding of the LC is undergoing a dramatic shift due to the application of state-of-the-art methods that reveal a nucleus of many modules that provide targeted neuromodulation. Here, we review the evidence supporting a modular LC based on multiple levels of observation (developmental, genetic, molecular, anatomical, and neurophysiological). We suggest that the concept of the LC as a singular nucleus and, alongside it, the role of the LC in diverse theories of brain function must be reconsidered.

Key words: locus coeruleus; stress; pain; anxiety; executive function; development

\section{Introduction}

The locus coeruleus (LC), a brainstem pontine nucleus of noradrenergic neurons, was identified in the human brain $>200$ years ago (Fig. 1). Writing in the first journal of German physiology (Reil, 1809; p 511, second paragraph), Johann Christian Reil described his observation: "The anterior extremity of the anterior shank [the Pedunculus cerebellaris superior]... forms, together with the anterior Marksegel [the Velum medullare superior], the roof of the fourth ventricle. In the angle at which the anterior shank comes together with the adjoining area, a stripe of black substance shimmers through, only covered by the epithelium." Reil is referring to the epithelium covering the floor of the fourth ventricle, where the LC is located. He continues: "Only in two

Received June 24, 2019; revised July 30, 2019; accepted Aug. 3, 2019.

A.E.P. was supported by Wellcome Trust Senior Clinical Fellowship Grant 0888373. J.G.M. was supported by the McDonnell Center for Systems Neuroscience. L.A.S. was supported by American Lebanese Syrian Associated Charities and the Rita Allen Foundation. P.J. was supported by the Intramural Research Program of the National Institutes of Health, National Institute of Environmental Health Sciences. D.J.C. was supported by the Department of Cell Biology and Neuroscience, Rowan University School of Medicine. N.K.T. was supported by the Department of Physiology of Cognitive Processes at the Max Planck Institute for Biological Cybernetics and the Helsinki Institute of Life Science.

The authors declare no competing financial interests.

Correspondence should be addressed to Nelson K. Totah at nelson.totah@tuebingen.mpg.de.

https://doi.org/10.1523/JNEUROSCI.1164-19.2019

Copyright $\odot 2019$ the authors places in the brain one finds black substance, here, as well as on the shanks before the bridge [the pons]. .. ." (translation by Prof. Almut Schüz at the Max Planck Institute for Biological Cybernetics in Tübingen, Germany; italics added with modern anatomical names). The location of the second area he refers to is consistent with the location of the substantia nigra. These black areas were visible in the human brain macroscopically without staining or microscopy. A few years later, the physicians and brothers Joseph and Karl Wenzel made a similar observation and, communicating their observations in Latin, thus described the Loci caerulei, that is, "blue spots" on either side of the brainstem that are now referred to in the singular as the LC (Wenzel and Wenzel, 1812). The original illustrations are shown in Figure 1. The black shimmering substance observed in this incipient research was later discovered to be neuromelanin, a pigment that is thought to be a result of dopamine synthesis (as well as noradrenaline since it is produced from dopamine) (Foley and Banter, 1958; Bazelon et al., 1967; Double et al., 2008).

In the 1960s and 1970s, with the advent of a histochemical reaction that caused catecholamines to fluoresce yellow-green (Falck et al., 1962; Dahlstroem and Fuxe, 1964), as well as a fluorescent antibody for the noradrenaline synthesis enzyme (Hartman, 1973), and autoradiographic methods (Jones and Moore, 


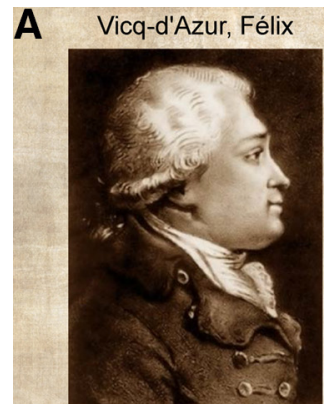

Paris, 1786

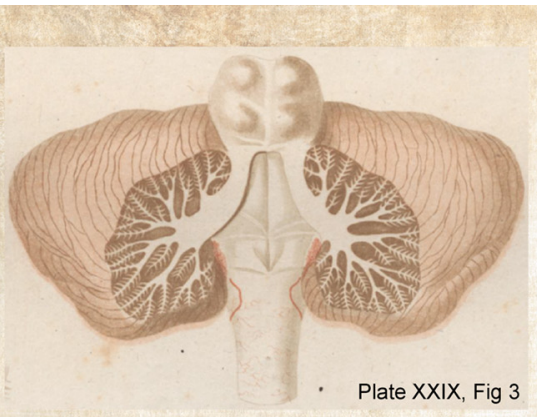

"Traité d'anatomie et de physiologie"

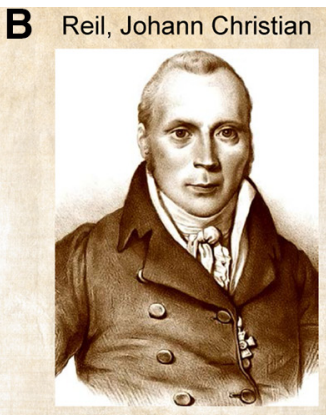

Halle, 1809

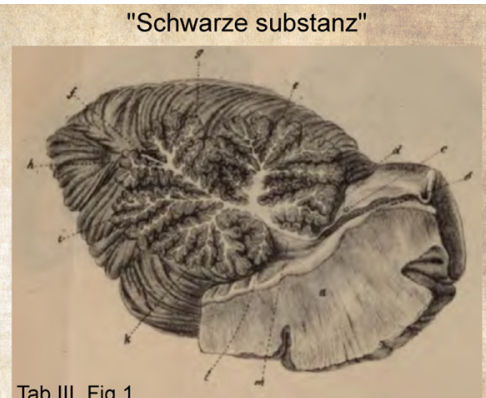

Tab III, Fig 1

"Untersuchungen über den Bau des grossen Gehirns im Menschen"

C Joseph and Carl Wenzel

ff. Loci caerulei, ad anteriorem partem baseos quinti ventriculi siti, de quibus

JOSEPIUS ET CAROLUS WFNZFL

DE PENITIORI

STRUCTURA CEREBRI HOMINIS ET BRUTORUM

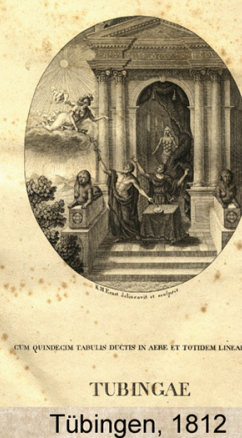
supra XVII. mentionem fecimus.

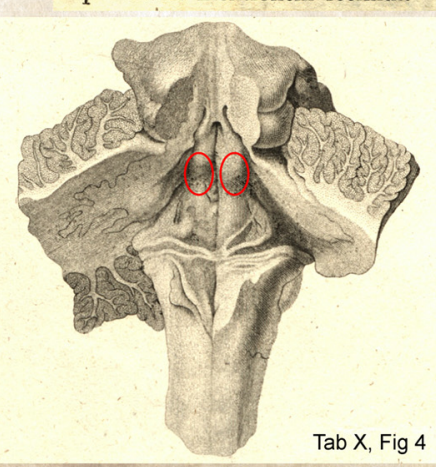

"De penitiori structura cerebri hominis et brutorum"

Figure 1. Drawings of the pons by Vicq-d'Azur (1786); Reil (1809), and Wenzel and Wenzel (1812) and identification of a darkly pigmented area, which was named the Loci caerulei. A, Vicq-d'Azur produced detailed drawings of the gross anatomy of the human brain, noting a pigmented area, the locus niger crurum cerebri, which is consistent with the substantia nigra. $\boldsymbol{B}$, Reil (1809) reported a "schwarze substanz" (black substance) in two areas consistent with the substantia nigra and the locus coeruleus. C, The Wenzel brothers also reported a pigmented structure on the roof of the pons under the fourth ventricle, naming it the Loci caerulei from which the locus coeruleus takes its name. The label "ff" refers to the Loci caerulei in the drawings (found in Table X in the book). We have highlighted this area with red ovals. The structure name is on page 341 and is presented as Figure 4 ("Figura quarta," p 340) in Table 10 ("Tabula decima," p339). Figure provided by N.K.T. and Stefan Hirschberg.

1977; Jones et al., 1977), these pigmented neurons were shown to be noradrenergic and to project broadly, even "globally," ascending across nearly the entire forebrain and descending, too, into brainstem and spinal cord (Swanson and Hartman, 1975; Grzanna et al., 1977; Fallon et al., 1978; Morrison et al., 1979). This led to the concept of the LC as being part of the central arousal system, preparing the brain for effortful cognitive action. Given its diffuse projections, it came as no surprise, then, that this small brainstem nucleus was involved in myriad brain functions. Subsequent electrophysiology and lesion studies demonstrated activation of the LC in the contexts of wakefulness (Foote et al., 1980; Aston-Jones and Bloom, 1981), the orienting reflex (Foote et al., 1980; Grant et al., 1988; Aston-Jones et al., 1994; Bouret and Sara, 2004), flexible cognition involving shifting attention (Aston-Jones et al., 1994), sensory gating (Waterhouse and Woodward, 1980; Waterhouse et al., 1990, 1998; Devilbiss and Waterhouse, 2004), invigorating of goal-directed activity (Anlezark et al., 1973), analgesia (Hirschberg et al., 2017), pain and stress (Igarashi et al., 1979; Elam et al., 1986; Valentino et al., 1991; Hirata and Aston-Jones, 1994; Mana and Grace, 1997; Sajedianfard et al., 2005; Hickey et al., 2014; McCall et al., 2015), and fear conditioning as well as fear extinction learning (Mueller et al., 2008; Uematsu et al., 2017; Giustino et al., 2019).

A central question that LC research has oft considered is how a broadly projecting nucleus could affect any singular function without affecting them all. For example, LC activation triggers awakening and arousal (Carter et al., 2010; Hayat et al., 2019), which is associated with enhanced sensory discrimination (Aston-Jones et al., 1994; Martins and Froemke, 2015) and lowered sensory neuron response thresholds (Waterhouse et al., 1990, 1998; Manunta and Edeline, 1998, 2004; Bouret and Sara, 2002; Devilbiss and Waterhouse, 2004; Devilbiss et al., 2006; Edeline et al., 2011; Navarra et al., 2013), but this sits at odds with the observation that LC activation is also associated with suppression of nociceptive sensory inputs (analgesia). This apparent paradox is readily demonstrable in attentional analgesia paradigms in humans where LC activity is associated with the interaction between attention (increased visual sensory discrimination) and analgesia (diminished nociceptive percept) (Brooks et al., 2017). One perspective, which has ample support, is that the LC alters global noradrenaline concentration and specific functional consequences are achieved through differences in postsynaptic receptors and regional differences in the spatiotemporal dynamics of noradrenaline reuptake (Berridge and Waterhouse, 2003; Agster et al., 2013; Giustino and Maren, 2018). However, a complementary view is now emerging that suggests that the LC may provide localized neuromodulation via LC neurons that have relatively circumscribed projection targets and synchronous spike timing among only subsets of LC neurons (for review, see Totah et al., 2019). In many ways, this perspective has parallels with the emerging conceptualization of the sympathetic nervous system as having discrete efferent limbs that are organ- or even targettissue-specific with characteristic patterns of activity (for review, see Jänig, 2006) but that also has the capability to act as a unified 
whole (Farmer et al., 2019). Similar parallels may be drawn with the dopaminergic system which, over the past decade, has become parcellated by cell type and by cell-specific afferents and efferents that allow this "diffuse" neuromodulatory system to contribute highly informative signals that govern specific cognitive processes (Lammel et al., 2012; Watabe-Uchida et al., 2012; Beier et al., 2015; Tian et al., 2016).

In this review, we will cover recent findings by the authors as well as others in the field of LC research that elaborates this emerging perspective using techniques that have made longstanding questions tractable for detailed investigation. For example, work in rats has demonstrated that subpopulations of LC neurons differentially project to the PFC and motor cortex (Chandler et al., 2013, 2014). Other work has demonstrated that subpopulations of LC neurons send separate projections to the basolateral amygdala (BLA) and infralimbic division of the PFC in rats, which may underlie the role of the LC in seemingly opposing functions of fear extinction and fear conditioning (Uematsu et al., 2017). Similarly, different subpopulations of LC neurons project to the spinal cord versus the PFC to mediate analgesia as opposed to aversion/anxiety, respectively (Li et al., 2016; Hirschberg et al., 2017). Of course, the capacity for targeted neuromodulation depends not only on projection specificity, but also on the degree to which spiking is desynchronized at the population level and synchronized only among subsets of LC neurons. High-channel density electrophysiology has demonstrated such ensemble firing patterns in the rat LC (Totah et al., 2018). Much of the recent progress is attributable to the innovative use of new methodological tools, such as novel retrograde tracing methods, functional manipulations of specific cell populations, and genetic fate mapping. We will review how these methods have advanced our understanding of the LC and its potential to regulate specific functions.

\section{Specific efferent pathways provide targeted neuromodulation of specific functions}

There are several accounts of a correlation between the morphology of individual LC neurons, their location within the nucleus, and their terminal projection fields. Mason and Fibiger (1979) first described an efferent topography of the nucleus in rats by injecting the retrograde tracer HRP into various structures throughout the neuraxis. They found that injections into hippocampus or septal nuclei consistently filled cells located in the dorsal, but not ventral, portion of the core of the LC nucleus, whereas injections into motor-related structures, such as caudate-putamen and cerebellum, labeled both ventral and dorsal portions. Injections into thalamus produced labeling in the posterior pole but not in more rostral portions, whereas hypothalamic injections labeled cells in the anterior pole. On the other hand, injections into amygdala and cortical structures, frontal regions in particular, produced labeling of neurons scattered throughout all three axes of the compact core of the nucleus (Mason and Fibiger, 1979; Loughlin et al., 1986a). These findings were confirmed and explored further by both Satoh et al. (1977) and Loughlin et al. (1986b) who showed that these subdivisions of LC, which have disparate efferent targets, also have morphologically distinct cells.

Experiments in which multiple retrograde tracers were injected into different structures in the same brain have yielded conflicting results. By pairing injections of different tracers into cortex and cerebellum, Nagai et al. (1981) showed that a small proportion of labeled LC cells contain axons innervating both structures, while most innervate one area or the other. This was corroborated by others who showed that pairs of injections into cortex and thalamus (Adèr et al., 1980) and cortex and cerebellum (Steindler, 1981) similarly produced small percentages of multilabeled neurons. On the other hand, Loughlin et al. (1982, 1986a) showed that injections of paired fluorescent retrograde tracers into various cortical regions yielded higher proportions of double-labeled LC neurons, especially when injections were made in the same or proximal mediolateral planes. They therefore concluded that single LC cell axons innervate multiple cortical regions as the projection spans mediolaterally across the cortex (Loughlin et al., 1982). An important implication of the work of Loughlin et al. (1982, 1986a) is that LC neurons have been thought to simply tile the cortex with mediolaterally running projections without regard to functional differences between the cortical targets.

More recently, it was shown that LC neurons innervate functionally related structures along ascending somatosensory pathways (Simpson et al., 1997), as well as in nociceptive pathways (Howorth et al., 2009a; Li et al., 2016). It was also shown by several investigators that the projection from LC to cortex is primarily ipsilateral (Jones and Moore, 1977; Mason and Fibiger, 1979; Waterhouse et al., 1983), whereas subcortical and spinal structures receive bilateral input from LC (Simpson et al., 1997; Howorth et al., 2009a). Collectively, these classic studies on LC efferent anatomy suggest that, despite having approximately uniform innervation patterns and function throughout the forebrain, the LC might be able to provide "semiglobal" neuromodulation through a partially targeted neuromodulatory system.

While many classic studies using immunohistochemistry or labeled dyes have characterized LC anatomy, the use of viral vectors and intersectional strategies has revolutionized the ability to trace LC neuroanatomy. This has been powerfully and comprehensively demonstrated through the Allen Mouse Brain Connectivity atlas (www.connectivity.brain-map.org) where the combination of vector-enabled labeling and serial 2-photon tomography have enabled whole brain reconstructions of projections (Oh et al., 2014). The power of this approach is illustrated with respect to the LC (Fig. 2). The selective expression of EGFP in the LC of a TH-Cre mouse line allows the extensive projection tree of the $\mathrm{LC}$ to be revealed, forming a global network of fibers across the brain (Fig. 2B,C). Parcellation of this projection on the basis of projection targets (i.e., olfactory bulb, visual cortex, hypothalamus, medulla) reveals a different perspective with individual fiber tracts targeting these different domains perhaps consistent with modular specialization (Fig. 2D). This methodology could, however, equally represent single LC neurons with enormously ramifying axons or, alternatively, that individual LC neurons have distinct projection targets. To address precisely this sort of question, a new viral-genetic neuroanatomical technique called MAPseq has been developed (Kebschull et al., 2016). MAPseq works by transducing a neuron population with a viral library expressing short, random RNA barcodes. Ideally, each neuron receives a single RNA barcode, which is amplified and trafficked to its projections via an axon targeting signal. To determine a neuron's brainwide projection pattern, barcodes are extracted from dissected brain regions and sequenced. MAPseq applied to the LC allowed the projections of these neurons to be resolved at a single-cell level. Overall, individual LC neurons were shown to have highly heterogeneous projection patterns, with some LC neurons projecting to a single brain area (consistent with a modular organization) and others projecting to many (achieving a broadcast signal). 


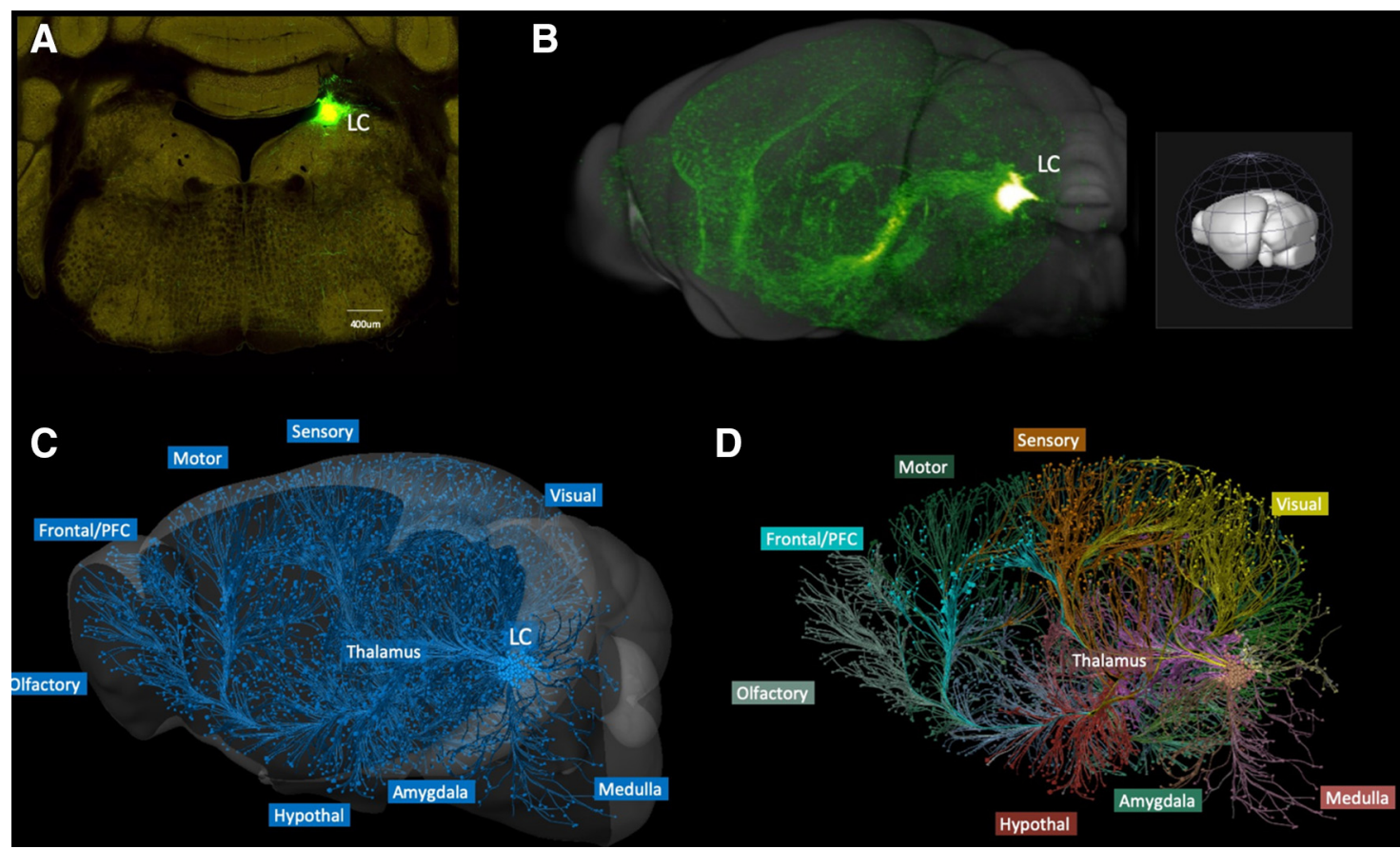

Figure 2. Reconstruction of $L C$ projections suggests a modular architecture. $A$, Expression of fluorophore in the right $L C$. $A$ Cre-dependent recombinant adeno-associated virus (AAV) expressing the fluorophore was injected into the mouse $\mathrm{LC}$ as an anterograde tracer. The mice were from a (re-driver line in which Cre recombinase is under control of the promotor for tyrosine hydroxylase ( $\mathrm{TH}$ ), an enzyme expressed by LC neurons as it is required for norepinephrine synthesis (Allen Brain Atlas Connectivity Project Experiment 511971714, TH-Cre_Fl172 mouse). B, After 2-photon serial tomography, the LC axonal projections were reconstructed in 3D. C, The distribution of the $\mathrm{LC}$ axons is seen to form an extensive network throughout the brain predominantly ipsilateral to the injection (contralateral hemisphere removed). D, Assignation of projection axons by target region reveals an architecture of distinct fiber trajectories consistent with the proposed modular organization. Figure provided by A.E.P.

These advances in viral technologies also make it possible to manipulate the activity of discrete neuron populations with unprecedented specificity in vivo. These methods have recently been applied to the LC to test the hypothesis that function-specific neuromodulation is achieved by subpopulations of LC neurons with unique anatomical connectivity in the brain. One approach has been to use the synthetic noradrenergic-neuronspecific promoter, PRS, to selectively express activity-modifying transgenes in LC neurons (Hwang et al., 2005; Lonergan et al., 2005; Howorth et al., 2009a,b; Hickey et al., 2014; Li et al., 2016; Hirschberg et al., 2017; Vazey et al., 2018; Cope et al., 2019; Xiang et al., 2019). Studies using PRS-containing canine adenoviral vectors (CAVs) (Junyent and Kremer, 2015) have been particularly helpful for dissecting the role of specific LC projections by enabling selective optogenetic or chemogenetic activation (Fig. 3). This approach allowed the analgesic effect of ponto-spinal LC neurons to be dissociated from an anxiety/aversive behavior produced by those projecting to the PFC (Hirschberg et al., 2017).

A similar viral strategy was used to uncover important diversity for LC projections related to cognitive behaviors.

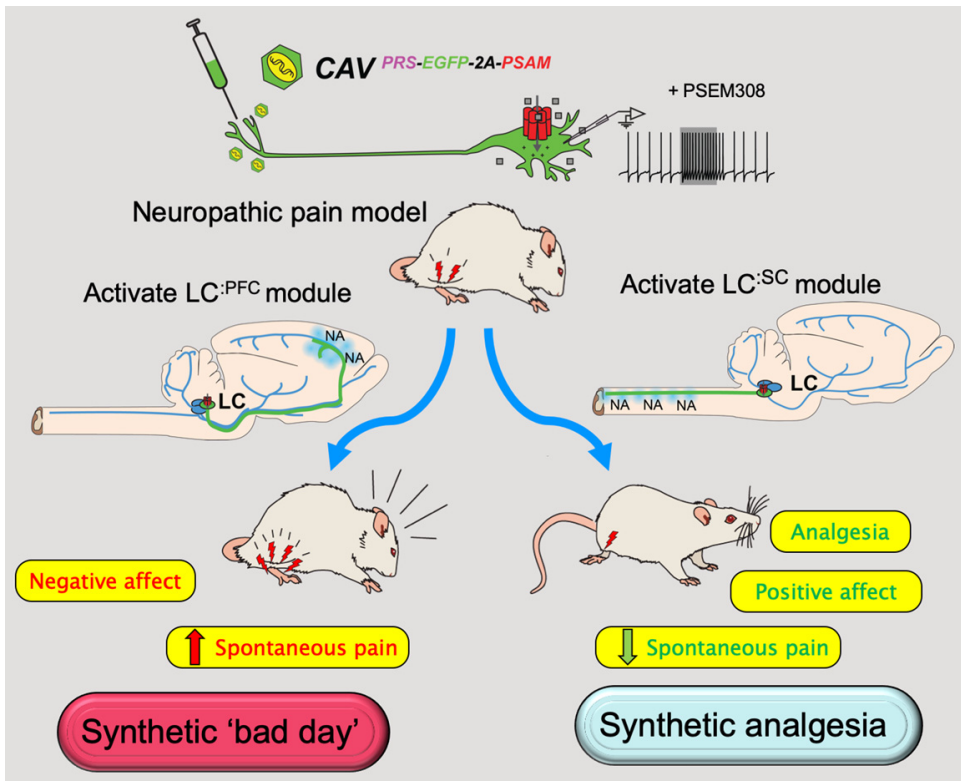

Figure 3. Selective chemogenetic activation of different $L C$ modules bidirectionally modifies the behavioral phenotype in a model of neuropathic pain. A retrograde targeting strategy with a CAV containing the PRS promoter was used by Hirschberg et al. (2017) to selectively express the excitatory chemogenetic actuator (PSAM, modified nicotinic ionophore) in LC modules. This enabled the selective activation (using the agonist PSEM308) of either spinal or PFC-projecting LC neurons during behavioral testing in the tibial nerve transection model of neuropathic pain. Activation of the spinally projecting $\mathrm{LC}$ module increased withdrawal thresholds, produced a positive affective bias, and reduced spontaneous pain behavior, consistent with a synthetic analgesic state. In contrast, activation of the PFC projection produced aversion and increased spontaneous pain behavior, which reflects a worsening of the pain phenotype and might be analogous to having a "bad pain day." This analgesic targeting of the spinal LC modules was equally effective preemptively (before nerve injury) and after the nerve injured and the pain phenotype had manifested. Figure provided by A.E.P. 

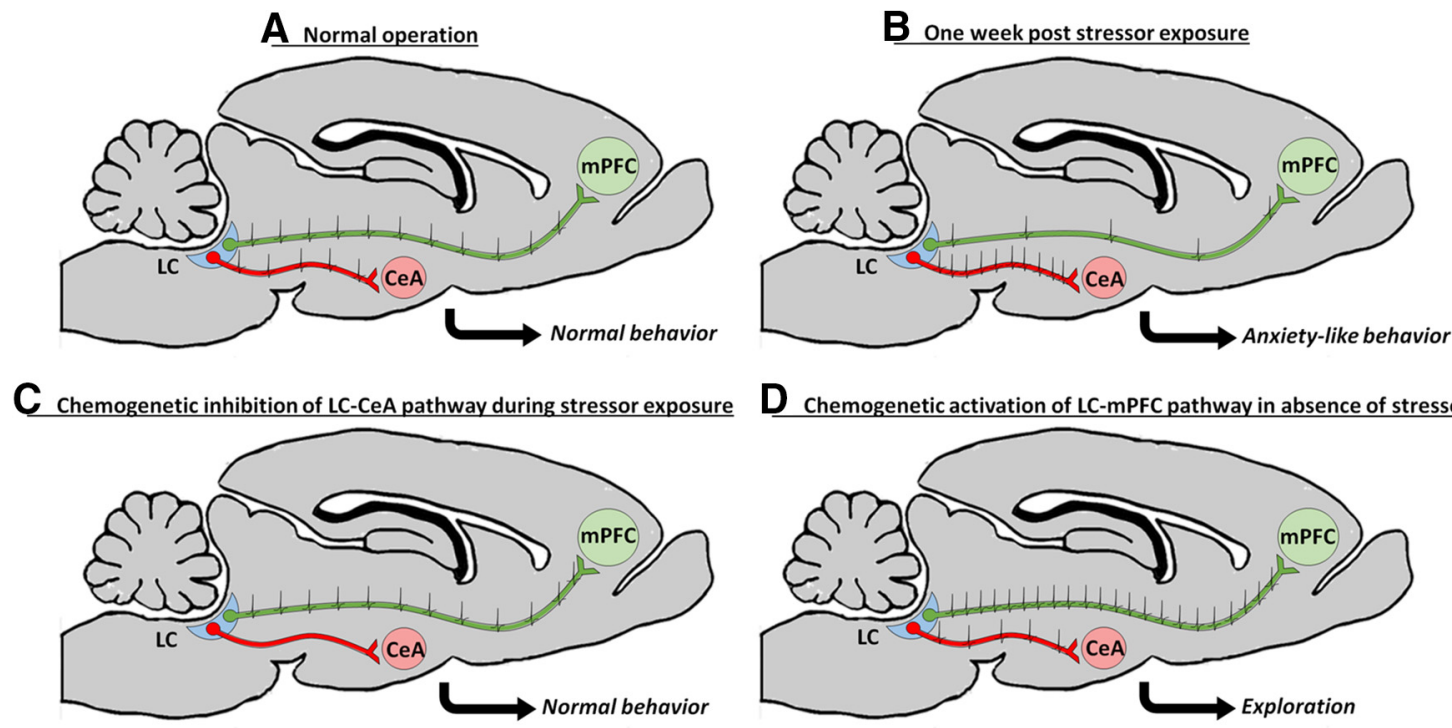

Figure 4. LC projections to PFC and CeA operate in parallel to guide behavior. $A$, Following normal conditions that do not elicit anxiety-like behavior in male rats, LC cells innervating PFC and CeA show similar levels of spontaneous discharge as assessed by ex vivo whole-cell patch-clamp electrophysiology. The level of spontaneous spiking is illustrated by spiking superimposed on the projection fibers. $\boldsymbol{B}$, One week after a single stressful episode (simultaneous physical restraint and exposure to the predator odor 2,5-dihydro-2,4,5-trimethylthiazoline), rats show increased anxiety-like behavior in the open field. Whole-cell patch-clamp recordings show that LC cells innervating CeA become hyperactive and hyperexcitable, whereas those projecting to PFC show a suppression of activity and excitability 1 week after stressor exposure. C, Injection of CAV-PRS-Cre into either region, followed by an injection of Cre-inducible AAVs to drive expression of designer receptors exclusively activated by designer drugs, (DREADDs) (Roth, 2016) permits manipulation of discrete LC efferent pathways. Inhibition of the LC-CeA pathway during stressor exposure prevents the development of an anxiety-like behavioral phenotype. D, Conversely, activation of the LC-PFC pathway in the absence of a stressor promotes exploration and loss of avoidance of open arms in the elevated plus maze. Figure provided by D.J.C.

Pairing injections of a CAV encoding Cre recombinase (CAVCre) at specific LC output sites with injections of Cre-dependent viral vectors into the $\mathrm{LC}$, researchers were able to express optogenetic activators or inhibitors exclusively in LC neurons projecting to the BLA or to the PFC (Uematsu et al., 2017). This allowed the researchers to distinguish the contribution of discrete LC projections to fear and extinction learning. Optogenetic activation of BLA-projecting LC neurons enhanced learning the association between a conditioned stimulus and the unconditioned shock, whereas activating PFC-projecting LC neurons facilitated extinction learning when the shock was no longer administered. Inhibiting these projections at their terminals had the opposite effect: fear learning was reduced, and extinction learning was enhanced. Of significant interest was that inhibiting LC neurons via their terminals had a greater effect on fear-conditioning-related behaviors than indiscriminate inhibition of all LC neurons at their cell bodies, suggesting that manipulating the entire LC may activate opposing frontal-subcortical noradrenergic circuits that could confound behavioral interpretations when activating the LC en masse. Similar targeted chemogenetic approaches have demonstrated that the LC-BLA pathway is associated with anxiety and anxiety evoked in rodent models of chronic pain (McCall et al., 2017; LlorcaTorralba et al., 2019). Activation of LC neurons with specific efferent targets versus activation of the entire LC may have differential and even opposite effects on behavior. Such findings illustrate why systemic therapeutic strategies, that augment noradrenaline levels globally within the CNS, are likely to produce a mixed picture of benefits and side effects in patients that are proportionate to the levels of activity in each LC module. This unpredictably increases variability in response between patients and limits the clinical utility of such "globally targeted" noradrenergic-based therapeutics.

One area in which these new viral approaches have had a particular impact is in understanding noradrenergic neuro- modulation of PFC-dependent cognitive functions. Prior lesion work suggested that a subpopulation of LC cells innervates subdivisions of the rat PFC to modulate extra-dimensional setshifting (a type of flexible learning-related behavior) and minimally collateralizes to other PFC subregions involved in other forms of behavioral flexibility (Newman et al., 2008). In line with this idea, early anatomical work had demonstrated that release of noradrenaline from LC efferents is not necessarily consistent throughout the brain: the density of varicosities along noradrenergic fibers is higher in frontal cortex than in motor, somatosensory, and piriform cortices (Agster et al., 2013). New methods have further developed these ideas. Cope et al. (2019) demonstrated that chemogenetic stimulation of LC terminals in PFC facilitates extra-dimensional set-shifting. Moreover, Tervo et al. (2014) have demonstrated that chemogenetic activation of LC neurons projecting to the anterior cingulate cortex promotes stochastic, rather than strategic, behavioral choices.

It has also been suggested that LC neurons projecting to some targets (e.g., the PFC or ACC) differ in their transcriptional and electrophysiological properties from LC neurons projecting to other forebrain targets (e.g., motor cortex) (Chandler et al., 2014). Specifically, cells innervating PFC were found to express higher levels of various genes related to excitability, synaptic transmission, and transmitter synthesis and release than LC cells innervating other cortical regions. In line with these observations, LC-PFC projection cells were found to be more active and excitable and to receive more excitatory synaptic input than other LC cells. Given the difference in excitability between these LC subpopulations, a crucial next step will be to elucidate the specific afferent inputs to these LC subpopulations that may contribute to their activity differences.

Recent unpublished observations by Chandler and colleagues provide further evidence for a modularly organized LC wherein PFC-projecting neurons promote exploration while central 
amygdala (CeA) projecting neurons promote anxiety-like behavior (Fig. 4A). Additional data suggest that these two subsets of LC neurons undergo opposing physiological adaptations in response to acute stressor exposure to mediate chronic changes in anxietylike behavior (Fig. $4 B-D$ ). However, it is important to note that parsing the modularity of LC-mediated anxiety-like behavior may prove to be a difficult task as there is already overlap in the behavioral output mediated by separate efferent projections. Anxiety-like behaviors can be driven by exogenous activation of LC cell bodies (McCall et al., 2015; Sciolino et al., 2016; Li et al., 2018; Zerbi et al., 2019), as well as by activating efferent projections to the BLA, PFC, and superior colliculus (Hirschberg et al., 2017; McCall et al., 2017; Li et al., 2018; Llorca-Torralba et al., 2019). Whether these evoked behaviors are equivalent is difficult to discern when viewed through the lens of a single or small set of related behavioral tasks. Fortunately, the specificity and in vivo applicability of viral tools, in combination with microendoscopebased calcium imaging, make it possible to characterize in detail both the activity of LC projections to specific targets and the afferents that drive activity in that subpopulation of LC neurons during multiple behavioral tests.

In summary, current state-of-the-art methods for circuit analysis suggest that at least some populations of LC neurons are more regionally restricted in their axonal collateralization than initially believed, and this can promote specificity in behavioral control. Consequently, the LC has come to be viewed as a modularly organized nucleus capable of segregating several distinct, complex sensory and behavioral functions among subsets of anatomically defined neurons with unique efferent projection fields.

\section{Developmental and genetic characteristics of LC neurons, defining modular architecture?}

Using information about efferent projections as a starting point for activating or inhibiting different subpopulations of LC neurons has revealed that the LC is functionally ordered and modular; however, this circuit-based approach is dependent on the use of viral constructs and is therefore typically used in juvenile and adult animals. An alternative strategy for uncovering heterogeneity is based on genetic neuroanatomy, specifically: correlating embryonic gene expression with adult brain structure and function (Joyner and Sudarov, 2012). Unlike the circuit-based approach, genetic neuroanatomy potentially allows reproducible access to subsets of LC neurons across developmental stages (albeit typically restricted to mouse). Genetic neuroanatomy is revealed through an approach termed "genetic fate mapping," which uses cell-type-specific expression of recombinases to switch on a reporter transgene as a lineage tracer (for review, see Jensen and Dymecki, 2014).

For the noradrenergic system, a Cre/loxP and flp/frt dualrecombinase-mediated intersectional genetic fate-mapping strategy was used to subdivide the mature system based on gene expression differences along the anteroposterior axis of the embryonic hindbrain. Populations of noradrenergic neurons were delineated by genes defining unique progenitor domains of the embryonic hindbrain and by subsequent expression of the noradrenergic marker dopamine $\beta$-hydroxylase (Robertson et al., 2013). Using this approach, four subsets of neurons were identified, each distinct in their anatomical distribution and efferent projection pattern. In addition, an unexpected projection to the orbital frontal cortex and insular cortex was found arising from outside of the LC, contradicting the dogmatic view that the LC is the lone noradrenergic nucleus projecting to the cortex
(Robertson et al., 2013). Although this fruitful analysis provided multiple molecular points of entry to study the noradrenergic system, the analysis revealed limited molecular heterogeneity within the LC. Greater than 99\% of LC-NE neurons are derived from the embryonic hindbrain progenitor domain defined by En1 expression. While this finding has allowed noninvasive and reproducible genetic access to study LC function in isolation from all other central and peripheral noradrenergic neurons (Sciolino et al., 2016; Chen et al., 2019), uncovering heterogeneity within the En1-defined LC would require new genetic tools.

Building on the cre/loxP and flp/frt dual-recombinase-based intersectional genetic strategy developed by Awatramani et al. (2003), dre/rox was used to develop a triple-recombinaseresponsive indicator allele (Plummer et al., 2015). Using this new indicator allele, the LC, as defined by a history of En1 and dopamine $\beta$-hydroxylase expression, can be further subdivided by a third gene expression domain for experimental study. The circuit approach can be merged with genetic fate mapping by virally delivered recombinase injected into LC targets. Thus, LC modules defined by efferent projections and function can be experimentally subdivided further by developmental or adult gene expression.

This approach was recently used to reveal that developmental gene expression generates differences in LC efferent neuronal circuitry. The triple-recombinase-based fate-mapping approach was used to subdivide the En1 progenitor domain along the dorsoventral axis, using $\operatorname{Pax} 7$ as a marker of the dorsal alar plate of the neural tube. In the adult brain, LC neurons with a history of Pax7 expression are intermingled with Pax7-negative LC neurons (Plummer et al., 2017). Although these two LC neuronal populations are intermingled throughout the extent of the rostrocaudal and dorsoventral axes of the LC, they differ in their efferent projection profiles, suggesting that they may be functionally distinct. Both populations project to most cortical regions, but whereas Pax7-positive LC neurons project to the thalamus, the projection from $\mathrm{Pax} 7$-negative LC neurons is extremely sparse to virtually absent. While this finding highlights the interaction of development and LC efferents in the formation of LC modules, the ultimate impact of this specific finding on behavioral function is unclear. New tools that bridge developmental genetic neuroanatomy and efferent projections to define and functionally manipulate LC modules promise to increase the resolution at which complex systems like the LC can be functionally dissected.

The emerging data on the genetic profile of LC neurons (Robertson et al., 2013; Chandler et al., 2014; Plummer et al., 2015, 2017; Mulvey et al., 2018; Chen et al., 2019) and the explosion in techniques for genetic neuroanatomy are likely to identify more genes that are differentially expressed across LC modules, such as axon guidance molecules, neurotransmitter receptors, and cotransmitter peptides. Ongoing studies of gene expression at the single-cell level must be extended throughout development, and combined with LC projection tracing, for a clear and complete picture of this complex system.

\section{Afferent circuitry may constrain LC efferent modules}

Extensive exploration of how afferents integrate with LC microcircuits to activate specific, efferent-defined LC modules is necessary for understanding how the LC functions as a collection of modules. The inputs to the LC are not as globally diffuse as its efferent network, but it does receive input from $>100$ brain regions assessed in mice (Schwarz et al., 2015) and from a broad array of regions assessed in separate tracing studies in rats and monkeys (Aston-Jones et al., 1991). To study the input-output 
mapping in the LC, researchers recently developed a combinatorial viral-genetic tracing tool called TRIO, which allows one to perform trans-synaptic rabies tracing from subsets of neurons defined by cell type and projection pattern (Schwarz et al., 2015). This work revealed that a majority of LC neurons receive similar input regardless of their projection target. On the other hand, recent work has provided an example of separate LC afferents evoking different LC-related behaviors (Yackle et al., 2017). While it has long been known that the LC response to severe stressors is driven by afferents from the paragigantocellular nucleus and the nucleus prepositus hypoglossi (Aston-Jones et al., 1986, 1991), recent work using TRIO-based viruses has demonstrated that the mild arousal evoked by a novel environment appears to be driven exclusively by $C d h 9 / D b x 1$ neurons in the breathing-related pre-Bötzinger complex (Yackle et al., 2017). Thus, different behavioral contexts may activate specific LC afferents; yet it is unknown how specific inputs affect the activity of subpopulations of LC neurons and the corresponding LC targetspecific output.

In terms of neurochemical-selective manipulation of inputs to the LC, most work has focused on neuropeptide systems. Here, building on a strong background of anatomical and neurochemical studies, multiple groups have shown diverging functions of hypothalamic and amygdalar projections to the LC (Horvath et al., 1999; Reyes et al., 2006, 2008, 2011; Kravets et al., 2015). Hypothalamic hypocretin projections appear to modulate both arousal (Carter et al., 2012) and fear learning (Sears et al., 2013), whereas specific CeA input to the LC appears to robustly drive anxiety-like and aversive behaviors (McCall et al., 2015; Reyes et al., 2015) via stress-related corticotropin releasing hormone (Curtis et al., 1997, 2012; Lechner et al., 1997; Jedema and Grace, 2004; Devilbiss et al., 2012; Prouty et al., 2017). Corticotropin releasing hormone release in the LC dose-dependently alters glutamate responsivity of LC neurons (Prouty et al., 2017). Importantly, this potentially enables corticotropin releasing hormone to "tune" glutamatergic afferents in a way that may activate LC modules with function-specific efferents. The LC receives multiple glutamatergic afferents (from paragigantocellularis nucleus, lateral habenula, and PFC) (Herkenham and Nauta, 1979; Arnsten and Goldman-Rakic, 1984; Aston-Jones et al., 1986; Holloway et al., 2013). Activation of these afferents is associated with the onset of salient or goal-relevant stimuli (Aston-Jones et al., 1994; Bouret and Sara, 2004), as well as affective disorders, opiate withdrawal, and neuropathic pain (Aghajanian et al., 1994; Hayashida et al., 2010; Bernard et al., 2011; Chandley et al., 2014; Kimura et al., 2015). Elevated expression of NMDA ionotropic and metabotropic glutamate receptors in the LC have been observed in postmortem tissue from suicide victims, suggesting that such input-output-specific LC modules, activated by particular neurochemicals, may play a role in major depressive disorder (Bernard et al., 2011; Chandley et al., 2014). Similarly, recent evidence suggests that increased availability of metabotropic glutamate receptor 5 (mGluR5) is associated with suicide ideation in patients with post-traumatic stress disorder (Davis et al., 2019).

In light of these important implications for neuropsychiatric disorders, future studies will need to delve deeper into LC afferent pathways, their neurochemical identity, and how receptor subtypes are modularly organized within the LC. The emerging approach of defining LC modules by their receptor complement is exemplified by experiments demonstrating genetic differences underlying the higher glutamate-mediated excitability of LC neurons that project to the motor cortex (Chandler et al., 2014).
Overall, it is clear that parsing the LC based on distinct projections, whether afferent or efferent, seems to hold some promise for identifying emergent properties of functional modules.

\section{LC ensemble activity patterns permit targeted neuromodulation}

Targeted neuromodulation by subpopulations of LC neurons could be achieved by LC neurons that do not spike synchronously (in addition to targets expressing different adrenergic receptors or differential densities of noradrenergic release sites). Longstanding evidence using single electrode recordings had suggested that LC neurons spike in population synchrony to achieve the global neuromodulation necessary for functions, such as wakefulness (Foote et al., 1980; Aston-Jones and Bloom, 1981). One study in the awake monkey had suggested that, among 23 pairs of LC neurons, levels of synchrony could fluctuate depending on cognitive state (Usher et al., 1999). Recent work using silicone probes with a high-channel density circumvented the limitation of single electrode recordings, allowing researchers to observe large-scale LC single-unit population activity for the first time (Totah et al., 2018, 2019). Importantly, by assessing $>3000$ cell pairs, this method revealed that an ensemble code does exist in the LC. Specifically, LC neurons were found to have overall little population synchrony. Moreover, the limited pairwise synchrony that existed occurred over specific timescales: submillisecond, tens of milliseconds, and infra-slow (multisecond) oscillatory synchrony. The authors speculate that these various timescales may relate, respectively, to gap junction connectivity, shared afferent inputs, and regulation of cortical networks formed by correlations of fMRI BOLD or mesoscale (e.g., local field potential) signals across brain regions. Totah et al. (2018, 2019) also used graph theoretic analyses to look beyond pairwise synchrony and demonstrate an LC ensemble code. Importantly, neurons with synchronous activity tended to project to functionally related forebrain regions; thus, an ensemble code combined with the efferent topography described above may permit a truly targeted neuromodulatory signal from the LC. Recordings of LC single-unit activity with high-channel-density electrophysiology in the awake, behaving animal is a crucial next step in understanding the signal conveyed by the modular architecture of the LC.

\section{Charting a path forward by developing a multilevel understanding of the LC}

A coherent and comprehensive picture of the LC will integrate multiple levels of observation across the noradrenergic system, including (1) the genotype and molecular/neurochemical phenotype of LC neurons, (2) their local interactions and ensemble activity patterns, and (3) the anatomy of their inputs and outputs and how these contribute to LC neuronal activity patterns in the context of various LC-associated functions. Such information can be used to inform and constrain existing and emerging models of noradrenergic neuromodulation that have not yet considered the implications of the modular LC architecture (AstonJones and Cohen, 2005a,b; Bouret and Sara, 2005; Yu and Dayan, 2005; Sales et al., 2019).

Such a path forward, with regard to genotype and molecular/ neurochemical phenotype, is exemplified by recent work on LC galanin neurotransmission, stress, and anxiety (McCall et al., 2015), differences in gene expression depending on LC neuron projection target (Chandler et al., 2014), and new tools that combine genetic fate mapping and tracing of LC projections (Plummer et al., 2017). These methods reveal function-specific LC 
modules that differ in projection target and genotype. However, LC neurons produce a multitude of neurochemicals and express a variety of genes (Mulvey et al., 2018). A better understanding of this level of diversity in the LC will allow the development and targeted deployment of research tools and pharmacological probes that can assess the functional roles of distinct LC neuronal subpopulations. This is likely to be of importance and utility in a wide range of disease states associated (at least partly) with the LC that range the developmental spectrum, such as attention-deficit and hyperactivity disorder, anxiety, depression, post-traumatic stress disorder, pain, Parkinson's disease, and dementia. Each of these neuropsychiatric disorders has plausible theories and demonstrable evidence of noradrenergic dysregulation, yet this manifests predominantly in particular domains, such as memory, movement, sensory processing, sleep disturbance, and emotional lability that may or may not be shared across these disorders. Treatments that can selectively target modular aspects of the LC noradrenergic system have a compelling logic that may enable a more effective amelioration of symptoms in specific domains with fewer side effects.

How many modules are contained within the several thousand neurons of the rodent LC (or indeed the estimated 60,000 of the primate/human brain) and how these modules can be engaged combinatorically or differentially remain to be determined. Understanding the intra-LC microcircuitry that allows the LC to activate modules independently (i.e., at different times) will require high-channel-density in vivo electrophysiology (Totah et al., 2018) to be combined with in vitro characterization of LC membrane properties and with optogenetic and chemogenetic activation of LC modules defined by their specific afferents and efferents using retrograde viruses and genetic fate mapping. Moreover, tools that identify brain states associated with activation of specific LC modules or enable profiling of discrete sites of transmitter release will be vital to resolving the functions of LC modules (Lovett-Barron et al., 2017; Feng et al., 2019; Zerbi et al., 2019).

Understanding of LC function will require an effort to integrate across levels, which necessitates collaboration among diverse scientists with different expertise, ideas, and perspectives. It is our hope, therefore, that new combinations of scientists and tools will be brought together to peer inside Reil's and the Wenzels' shimmering dark spot (Reil, 1809; Wenzel and Wenzel, 1812). If the nucleus, LC, is truly a collection of modules, then a return to the original nomenclature, the Loci Caerulei (Wenzel and Wenzel, 1812), the many nuclei, may be apropos.

\section{References}

Adèr PJ, Room P, Postema F, Korf J (1980) Bilaterally diverging axon collaterals and contralateral projections from rat locus coeruleus neurons, demonstrated by fluorescent retrograde double labeling and norepinephrine metabolism. J Neural Transm 49:207-218.

Aghajanian GK, Kogan JH, Moghaddam B (1994) Opiate withdrawal increases glutamate and aspartate efflux in the locus coeruleus: an in vivo microdialysis study. Brain Res 636:126-130.

Agster KL, Mejias-Aponte CA, Clark BD, Waterhouse BD (2013) Evidence for a regional specificity in the density and distribution of noradrenergic varicosities in rat cortex. J Comp Neurol 521:2195-2207.

Anlezark GM, Crow TJ, Greenway AP (1973) Impaired learning and decreased cortical norepinephrine after bilateral locus coeruleus lesions. Science 181:682-684.

Arnsten AF, Goldman-Rakic PS (1984) Selective prefrontal cortical projections to the region of the locus coeruleus and raphe nuclei in the rhesus monkey. Brain Res 306:9-18.

Aston-Jones G, Bloom FE (1981) Activity of norepinephrine-containing locus coeruleus neurons in behaving rats anticipates fluctuations in the sleep-waking cycle. J Neurosci 1:876-886.
Aston-Jones G, Cohen JD (2005a) Adaptive gain and the role of the locus coeruleus-norepinephrine system in optimal performance. J Comp Neurol 493:99-110.

Aston-Jones G, Cohen JD (2005b) An integrative theory of locus coeruleusnorepinephrine function: adaptive gain and optimal performance. Annu Rev Neurosci 28:403-450.

Aston-Jones G, Ennis M, Pieribone VA, Nickell WT, Shipley MT (1986) The brain nucleus locus coeruleus: restricted afferent control of a broad efferent network. Science 234:734-737.

Aston-Jones G, Shipley MT, Chouvet G, Ennis M, van Bockstaele E, Pieribone V, Shiekhattar R, Akaoka H, Drolet G, Astier B (1991) Afferent regulation of locus coeruleus neurons: anatomy, physiology and pharmacology. Prog Brain Res 88:47-75.

Aston-Jones G, Rajkowski J, Kubiak P, Alexinsky T (1994) Locus coeruleus neurons in monkey are selectively activated by attended cues in a vigilance task. J Neurosci 14:4467-4480.

Awatramani R, Soriano P, Rodriguez C, Mai JJ, Dymecki SM (2003) Cryptic boundaries in roof plate and choroid plexus identified by intersectional gene activation. Nat Genet 35:70-75.

Bazelon M, Fenichel GM, Randall J (1967) Studies on neuromelanin: I. A melanin system in the human adult brainstem. Neurology 17:512-519.

Beier KT, Steinberg EE, DeLoach KE, Xie S, Miyamichi K, Schwarz L, Gao XJ, Kremer EJ, Malenka RC, Luo L (2015) Circuit architecture of VTA dopamine neurons revealed by systematic input-output mapping. Cell 162: $622-634$.

Bernard R, Kerman IA, Thompson RC, Jones EG, Bunney WE, Barchas JD, Schatzberg AF, Myers RM, Akil H, Watson SJ (2011) Altered expression of glutamate signaling, growth factor, and glia genes in the locus coeruleus of patients with major depression. Mol Psychiatry 16:634-646.

Berridge CW, Waterhouse BD (2003) The locus coeruleus-noradrenergic system: modulation of behavioral state and state-dependent cognitive processes. Brain Res Brain Res Rev 42:33-84.

Bouret S, Sara SJ (2002) Locus coeruleus activation modulates firing rate and temporal organization of odour-induced single-cell responses in rat piriform cortex. Eur J Neurosci 16:2371-2382.

Bouret S, Sara SJ (2004) Reward expectation, orientation of attention and locus coeruleus-medial frontal cortex interplay during learning. Eur J Neurosci 20:791-802.

Bouret S, Sara SJ (2005) Network reset: a simplified overarching theory of locus coeruleus noradrenaline function. Trends Neurosci 28:574-582.

Brooks JC, Davies WE, Pickering AE (2017) Resolving the brainstem contributions to attentional analgesia. J Neurosci 37:2279-2291.

Carter ME, Yizhar O, Chikahisa S, Nguyen H, Adamantidis A, Nishino S, Deisseroth K, de Lecea L (2010) Tuning arousal with optogenetic modulation of locus coeruleus neurons. Nat Neurosci 13:1526-1533.

Carter ME, Brill J, Bonnavion P, Huguenard JR, Huerta R, de Lecea L (2012) Mechanism for hypocretin-mediated sleep-to-wake transitions. Proc Natl Acad Sci U S A 109:E2635-E2644.

Chandler DJ, Lamperski CS, Waterhouse BD (2013) Identification and distribution of projections from monoaminergic and cholinergic nuclei to functionally differentiated subregions of prefrontal cortex. Brain Res 1522:38-58.

Chandler DJ, Gao WJ, Waterhouse BD (2014) Heterogeneous organization of the locus coeruleus projections to prefrontal and motor cortices. Proc Natl Acad Sci U S A 111:6816-6821.

Chandley MJ, Szebeni A, Szebeni K, Crawford JD, Stockmeier CA, Turecki G, Kostrzewa RM, Ordway GA (2014) Elevated gene expression of glutamate receptors in noradrenergic neurons from the locus coeruleus in major depression. Int J Neuropsychopharmacol 17:1569-1578.

Chen YW, Das M, Oyarzabal EA, Cheng Q, Plummer NW, Smith KG, Jones GK, Malawsky D, Yakel JL, Shih YI, Jensen P (2019) Genetic identification of a population of noradrenergic neurons implicated in attenuation of stress-related responses. Mol Psychiatry 24:710-725.

Cope ZA, Vazey EM, Floresco SB, Aston Jones GS (2019) DREADDmediated modulation of locus coeruleus inputs to $\mathrm{MPFC}$ improves strategy set-shifting. Neurobiol Learn Mem 161:1-11.

Curtis AL, Leiser SC, Snyder K, Valentino RJ (2012) Predator stress engages corticotropin-releasing factor and opioid systems to alter the operating mode of locus coeruleus norepinephrine neurons. Neuropharmacology 62:1737-1745.

Curtis AL, Lechner SM, Pavcovich LA, Valentino RJ (1997) Activation of the locus coeruleus noradrenergic system by intracoerulear microinfu- 
sion of corticotropin-releasing factor: effects on discharge rate, cortical norepinephrine levels and cortical electroencephalographic activity. J Pharmacol Exp Ther 281:163-172.

Dahlstroem A, Fuxe K (1964) Evidence for the existence of monoaminecontaining neurons in the central nervous system: I. Demonstration of monoamines in the cell bodies of brain stem neurons. Acta Physiol Scand Suppl 232:1-55.

Davis MT, Hillmer A, Holmes SE, Pietrzak RH, DellaGioia N, Nabulsi N, Matuskey D, Angarita-Africano G, Carson RE, Krystal JH, Esterlis I (2019) In vivo evidence for dysregulation of mGluR5 as a biomarker of suicidal ideation. Proc Natl Acad Sci U S A 116:11490-11495.

Devilbiss DM, Waterhouse BD (2004) The effects of tonic locus coeruleus output on sensory-evoked responses of ventral posterior medial thalamic and barrel field cortical neurons in the awake rat. J Neurosci 24: 10773-10785.

Devilbiss DM, Page ME, Waterhouse BD (2006) Locus coeruleus regulates sensory encoding by neurons and networks in waking animals. J Neurosci 26:9860-9872.

Devilbiss DM, Waterhouse BD, Berridge CW, Valentino R (2012) Corticotropin-releasing factor acting at the locus coeruleus disrupts thalamic and cortical sensory-evoked responses. Neuropsychopharmacology 37:2020-2030.

Double KL, Dedov VN, Fedorow H, Kettle E, Halliday GM, Garner B, Brunk UT (2008) The comparative biology of neuromelanin and lipofuscin in the human brain. Cell Mol Life Sci 65:1669-1682.

Edeline JM, Manunta Y, Hennevin E (2011) Induction of selective plasticity in the frequency tuning of auditory cortex and auditory thalamus neurons by locus coeruleus stimulation. Hear Res 274:75-84.

Elam M, Svensson TH, Thorén P (1986) Locus coeruleus neurons and sympathetic nerves: activation by cutaneous sensory afferents. Brain Res 366 : $254-261$.

Falck B, Hillarp NÅ, Thieme G, Topr A (1962) Fluorescence of catechol amines and related compounds condensed with formaldehyde. J Histochem Cytochem 10:348-354.

Fallon JH, Koziell DA, Moore RY (1978) Catecholamine innervation of the basal forebrain: II. Amygdala, suprarhinal cortex and entorhinal cortex. J Comp Neurol 180:509-532.

Farmer DG, Pracejus N, Dempsey B, Turner A, Bokiniec P, Paton JF, Pickering AE, Burguet J, Andrey P, Goodchild AK, McAllen RM, McMullan S (2019) On the presence and functional significance of sympathetic premotor neurons with collateralized spinal axons in the rat. J Physiol 597: 3407-3423.

Feng J, Zhang C, Lischinsky JE, Jing M, Zhou J, Wang H, Zhang Y, Dong A, Wu Z, Wu H, Chen W, Zhang P, Zou J, Hires SA, Zhu JJ, Cui G, Lin D, Du J, Li Y (2019) A genetically encoded fluorescent sensor for rapid and specific in vivo detection of norepinephrine. Neuron 102:745-761.e8.

Foley JM, Banter D (1958) On the nature of pigment granules in the cells of the locus coeruleus and substantia nigra. J Neuropathol Exp Neurol 17: 586-598.

Foote SL, Aston-Jones G, Bloom FE (1980) Impulse activity of locus coeruleus neurons in awake rats and monkeys is a function of sensory stimulation and arousal. Proc Natl Acad Sci U S A 77:3033-3037.

Giustino TF, Maren S (2018) Noradrenergic modulation of fear conditioning and extinction. Front Behav Neurosci 12:43.

Giustino TF, Fitzgerald PJ, Ressler RL, Maren S (2019) Locus coeruleus toggles reciprocal prefrontal firing to reinstate fear. Proc Natl Acad Sci U S A 116:201814278.

Grant SJ, Aston-Jones G, Redmond DE Jr (1988) Responses of primate locus coeruleus neurons to simple and complex sensory stimuli. Brain Res Bull 21:401-410.

Grzanna R, Morrison JH, Coyle JT, Molliver ME (1977) The immunohistochemical demonstration of noradrenergic neurons in the rat brain: the use of homologous antiserum to dopamine-beta-hydroxylase. Neurosci Lett 4:127-134.

Hartman BK (1973) Immunofluorescence of dopamine-hydroxylase: application of improved methodology to the localization of the peripheral and central noradrenergic nervous system. J Histochem Cytochem 21: $312-332$.

Hayashida K, Parker RA, Eisenach JC (2010) Activation of glutamate transporters in the locus coeruleus paradoxically activates descending inhibition in rats. Brain Res 1317:80-86.

Hayat H, Regev N, Matosevich N, Sales A, Paredes-Rodriguez E, Krom AJ,
Bergman L, Li Y, Lavigne M, Kremer EJ, Yizhar O, Pickering AE, Nir Y (2019) Locus-coeruleus norepinephrine activity gates sensory-evoked awakenings from sleep. Advance online publication. Retrieved June 20, 2019. doi:10.1101/539502.

Herkenham M, Nauta WJ (1979) Efferent connections of the habenular nuclei in the rat. J Comp Neurol 187:19-47.

Hickey L, Li Y, Fyson SJ, Watson TC, Perrins R, Hewinson J, Teschemacher AG, Furue H, Lumb BM, Pickering AE (2014) Optoactivation of locus coeruleus neurons evokes bidirectional changes in thermal nociception in rats. J Neurosci 34:4148-4160.

Hirata H, Aston-Jones G (1994) A novel long-latency response of locus coeruleus neurons to noxious stimuli: mediation by peripheral C-fibers. J Neurophysiol 71:1752-1761.

Hirschberg S, Li Y, Randall A, Kremer EJ, Pickering AE (2017) Functional dichotomy in spinal- vs prefrontal-projecting locus coeruleus modules splits descending noradrenergic analgesia from ascending aversion and anxiety in rats. Elife 6:e29808.

Holloway BB, Stornetta RL, Bochorishvili G, Erisir A, Viar KE, Guyenet PG (2013) Monosynaptic glutamatergic activation of locus coeruleus and other lower brainstem noradrenergic neurons by the $\mathrm{C} 1$ cells in mice. J Neurosci 33:18792-18805.

Horvath TL, Peyron C, Diano S, Ivanov A, Aston-Jones G, Kilduff TS, van Den Pol AN (1999) Hypocretin (orexin) activation and synaptic innervation of the locus coeruleus noradrenergic system. J Comp Neurol 415: $145-159$.

Howorth PW, Teschemacher AG, Pickering AE (2009a) Retrograde adenoviral vector targeting of nociresponsive pontospinal noradrenergic neurons in the rat in vivo. J Comp Neurol 512:141-157.

Howorth PW, Thornton SR, O'Brien V, Smith WD, Nikiforova N, Teschemacher AG, Pickering AE (2009b) Retrograde viral vector-mediated inhibition of pontospinal noradrenergic neurons causes hyperalgesia in rats. J Neurosci 29:12855-12864.

Hwang DY, Carlezon WA Jr, Isacson O, Kim KS (2001) A high-efficiency synthetic promoter that drives transgene expression selectively in noradrenergic neurons. Hum Gene Ther 12:1731-1740.

Hwang DY, Hwang MM, Kim HS, Kim KS (2005) Genetically engineered dopamine beta-hydroxylase gene promoters with better PHOX2-binding sites drive significantly enhanced transgene expression in a noradrenergic cell-specific manner. Mol Ther 11:132-141.

Igarashi S, Sasa M, Takaori S (1979) Feedback loop between locus coeruleus and spinal trigeminal nucleus neurons responding to tooth pulp stimulation in the rat. Brain Res Bull 4:75-83.

Jänig W (2006) Integrative action of the autonomic nervous system. Cambridge University Press: Cambridge, New York.

Jedema HP, Grace AA (2004) Corticotropin-releasing hormone directly activates noradrenergic neurons of the locus coeruleus recorded in vitro. J Neurosci 24:9703-9713.

Jensen P, Dymecki SM (2014) Essentials of Recombinase-Based Genetic Fate Mapping in Mice. In: Lewandoski M. (eds) Mouse Molecular Embryology. Methods in Molecular Biology (Methods and Protocols), vol 1092. Humana Press:Boston, MA.

Jones BE, Moore RY (1977) Ascending projections of the locus coeruleus in the rat: II. Autoradiographic study. Brain Res 127:23-53.

Jones BE, Halaris AE, McIlhany M, Moore RY (1977) Ascending projections of the locus coeruleus in the rat: I. Axonal transport in central noradrenaline neurons. Brain Res 127:1-21.

Joyner AL, Sudarov A (2012) Genetic neuroanatomy. In: The mouse nervous system (Watson C, Paxinos G, Puelles L, eds), pp 36-50. San Diego: Academic Press.

Junyent F, Kremer EJ (2015) CAV-2-why a canine virus is a neurobiologist's best friend. Curr Opin Pharmacol 24:86-93.

Kebschull JM, Garcia da Silva P, Reid AP, Peikon ID, Albeanu DF, Zador AM (2016) High-throughput mapping of single-neuron projections by sequencing of barcoded RNA. Neuron 91:975-987.

Kimura M, Suto T, Eisenach JC, Hayashida K (2015) Down-regulation of astroglial glutamate transporter-1 in the locus coeruleus impairs painevoked endogenous analgesia in rats. Neurosci Lett 608:18-22.

Kravets JL, Reyes BA, Unterwald EM, Van Bockstaele EJ (2015) Direct targeting of peptidergic amygdalar neurons by noradrenergic afferents: linking stress-integrative circuitry. Brain Struct Funct 220:541-558.

Lammel S, Lim BK, Ran C, Huang KW, Betley MJ, Tye KM, Deisseroth K, 
Malenka RC (2012) Input-specific control of reward and aversion in the ventral tegmental area. Nature 491:212-217.

Lechner SM, Curtis AL, Brons R, Valentino RJ (1997) Locus coeruleus activation by colon distention: role of corticotropin-releasing factor and excitatory amino acids. Brain Res 756:114-124.

Li L, Feng X, Zhou Z, Zhang H, Shi Q, Lei Z, Shen P, Yang Q, Zhao B, Chen S, Li L, Zhang Y, Wen P, Lu Z, Li X, Xu F, Wang L (2018) Stress accelerates defensive responses to looming in mice and involves a locus coeruleussuperior colliculus projection. Curr Biol 28:859-871.e5.

Li Y, Hickey L, Perrins R, Werlen E, Patel AA, Hirschberg S, Jones MW, Salinas S, Kremer EJ, Pickering AE (2016) Retrograde optogenetic characterization of the pontospinal module of the locus coeruleus with a canine adenoviral vector. Brain Res 1641:274-290.

Llorca-Torralba M, Suárez-Pereira I, Bravo L, Camarena-Delgado C, GarciaPartida JA, Mico JA, Berrocoso E (2019) Chemogenetic silencing of the locus coeruleus-basolateral amygdala pathway abolishes pain-induced anxiety and enhanced aversive learning in rats. Biol Psychiatry 85: 1021-1035.

Lonergan T, Teschemacher AG, Hwang DY, Kim KS, Pickering AE, Kasparov S (2005) Targeting brain stem centers of cardiovascular control using adenoviral vectors: impact of promoters on transgene expression. Physiol Genomics 20:165-172.

Loughlin SE, Foote SL, Bloom FE (1986a) Efferent projections of nucleus locus coeruleus: topographic organization of cells of origin demonstrated by three-dimensional reconstruction. Neuroscience 18:291-306.

Loughlin SE, Foote SL, Grzanna R (1986b) Efferent projections of nucleus locus coeruleus: morphologic subpopulations have different efferent targets. Neuroscience 18:307-319.

Loughlin SE, Foote SL, Fallon JH (1982) Locus coeruleus projections to cortex: topography, morphology and collateralization. Brain Res Bull 9:287-294.

Lovett-Barron M, Andalman AS, Allen WE, Vesuna S, Kauvar I, Burns VM, Deisseroth K (2017) Ancestral circuits for the coordinated modulation of brain state. Cell 171:1411-1423.e17.

Mana MJ, Grace AA (1997) Chronic cold stress alters the basal and evoked electrophysiological activity of rat locus coeruleus neurons. Neuroscience 81:1055-1064.

Manunta Y, Edeline JM (1998) Effects of noradrenaline on rate-level function of auditory cortex neurons: is there a "gating" effect of noradrenaline? Exp Brain Res 118:361-372.

Manunta Y, Edeline JM (2004) Noradrenergic induction of selective plasticity in the frequency tuning of auditory cortex neurons. J Neurophysiol 92:1445-1463.

Martins AR, Froemke RC (2015) Coordinated forms of noradrenergic plasticity in the locus coeruleus and primary auditory cortex. Nat Neurosci 18:1483-1492.

Mason ST, Fibiger HC (1979) Regional topography within noradrenergic locus coeruleus as revealed by retrograde transport of horseradish peroxidase. J Comp Neurol 187:703-724.

McCall JG, Al-Hasani R, Siuda ER, Hong DY, Norris AJ, Ford CP, Bruchas MR (2015) CRH engagement of the locus coeruleus noradrenergic system mediates stress-induced anxiety. Neuron 87:605-620.

McCall JG, Siuda ER, Bhatti DL, Lawson LA, McElligott ZA, Stuber GD, Bruchas MR (2017) Locus coeruleus to basolateral amygdala noradrenergic projections promote anxiety-like behavior. Elife 6:e18247.

Morrison JH, Molliver ME, Grzanna R, Coyle JT (1979) Noradrenergic innervation patterns in three regions of medial cortex: an immunofluorescence characterization. Brain Res Bull 4:849-857.

Mueller D, Porter JT, Quirk GJ (2008) Noradrenergic signaling in infralimbic cortex increases cell excitability and strengthens memory for fear extinction. J Neurosci 28:369-375.

Mulvey B, Bhatti DL, Gyawali S, Lake AM, Kriaucionis S, Ford CP, Bruchas MR, Heintz N, Dougherty JD (2018) Molecular and functional sex differences of noradrenergic neurons in the mouse locus coeruleus. Cell Rep 23:2225-2235.

Nagai T, Satoh K, Imamoto K, Maeda T (1981) Divergent projections of catecholamine neurons of the locus coeruleus as revealed by fluorescent retrograde double labeling technique. Neurosci Lett 23:117-123.

Navarra RL, Clark BD, Zitnik GA, Waterhouse BD (2013) Methylphenidate and atomoxetine enhance sensory-evoked neuronal activity in the visual thalamus of male rats. Exp Clin Psychopharmacol 21:363-374.

Newman LA, Darling J, McGaughy J (2008) Atomoxetine reverses atten- tional deficits produced by noradrenergic deafferentation of medial prefrontal cortex. Psychopharmacology 200:39-50.

Oh S, Harris JA, Ng L, Winslow B, Cain N, Mihalas S, Wang Q, Lau C, Kuan L, Henry AM, Mortrud MT, Ouellette B, Nguyen TN, Sorensen SA, Slaughterbeck CR, Wakeman W, Li Y, Feng D, Ho A, Nicholas E, et al. (2014) A mesoscale connectome of the mouse brain. Nature 508: 207-214.

Plummer NW, Evsyukova IY, Robertson SD, de Marchena J, Tucker CJ, Jensen P (2015) Expanding the power of recombinase-based labeling to uncover cellular diversity. Development 142:4385-4393.

Plummer NW, Scappini EL, Smith KG, Tucker CJ, Jensen P (2017) Two subpopulations of noradrenergic neurons in the locus coeruleus complex distinguished by expression of the dorsal neural tube marker Pax7. Front Neuroanat 11:60.

Prouty EW, Waterhouse BD, Chandler DJ (2017) Corticotropin releasing factor dose-dependently modulates excitatory synaptic transmission in the noradrenergic nucleus locus coeruleus. Eur J Neurosci 45:712-722.

Reil J (1809) Untersuchungen fiber den Bau des grogen Gehirns im Menschen. Arch Physiol.

Reyes BA, Glaser JD, Magtoto R, Van Bockstaele EJ (2006) Pro-opiomelanocortin colocalizes with corticotropin-releasing factor in axon terminals of the noradrenergic nucleus locus coeruleus. Eur J Neurosci 23: 2067-2077.

Reyes BA, Zitnik G, Foster C, Van Bockstaele EJ, Valentino RJ (2015) Social stress engages neurochemically-distinct afferents to the rat locus coeruleus depending on coping strategy. eNeuro 2:ENEURO.0042-15.2015.

Reyes BA, Drolet G, Van Bockstaele EJ (2008) Dynorphin and stress-related peptides in rat locus coeruleus: contribution of amygdalar efferents. J Comp Neurol 508:663-675.

Reyes S, Carvalho AF, Vakharia K, Van Bockstaele EJ (2011) Amygdalar peptidergic circuits regulating noradrenergic locus coeruleus neurons: linking limbic and arousal centers. Exp Neurol 230:96-105.

Robertson SD, Plummer NW, de Marchena J, Jensen P (2013) Developmental origins of central norepinephrine neuron diversity. Nat Neurosci 16:1016-1023.

Roth B (2016) DREADDs for Neuroscientists. Neuron 89:683-694.

Sajedianfard J, Khatami S, Semnanian S, Naghdi N, Jorjani M (2005) In vivo measurement of noradrenaline in the locus coeruleus of rats during the formalin test: a microdialysis study. Eur J Pharmacol 512:153-156.

Sales AC, Friston KJ, Jones MW, Pickering AE, Moran RJ (2019) Locus coeruleus tracking of prediction errors optimises cognitive flexibility: an active inference model. Plos Comput Biol 15:e1006267.

Satoh K, Tohyama M, Yamamoto K, Sakumoto T, Shimizu N (1977) Noradrenaline innervation of the spinal cord studied by the horseradish peroxidase method combined with monoamine oxidase staining. Exp Brain Res 30:175-186.

Schwarz LA, Miyamichi K, Gao XJ, Beier KT, Weissbourd B, DeLoach KE, Ren J, Ibanes S, Malenka RC, Kremer EJ, Luo L (2015) Viral-genetic tracing of the input-output organization of a central noradrenaline circuit. Nature 524:88-92.

Sciolino NR, Plummer NW, Chen YW, Alexander GM, Robertson SD, Dudek SM, McElligott ZA, Jensen P (2016) Recombinase-dependent mouse lines for chemogenetic activation of genetically defined cell types. Cell Rep 15:2563-2573.

Sears RM, Fink AE, Wigestrand MB, Farb CR, de Lecea L, Ledoux JE (2013) Orexin/hypocretin system modulates amygdala-dependent threat learning through the locus coeruleus. Proc Natl Acad Sci U S A 110: $20260-20265$.

Simpson KL, Altman DW, Wang L, Kirifides ML, Lin RC, Waterhouse BD (1997) Lateralization and functional organization of the locus coeruleus projection to the trigeminal somatosensory pathway in rat. J Comp Neurol 385:135-147.

Steindler DA (1981) Locus coerules neurons have axons that branch to the forebrain and cerebellum. Brain Res 223:367-373.

Swanson LW, Hartman BK (1975) The central adrenergic system: an immunofluorescence study of the location of cell bodies and their efferent connections in the rat utilizing dopamine-beta-hydroxylase as a marker. J Comp Neurol 163:467-505.

Tervo DG, Proskurin M, Manakov M, Kabra M, Vollmer A, Branson K, Karpova AY (2014) Behavioral variability through stochastic choice and its gating by anterior cingulate cortex. Cell 159:21-32.

Tian J, Huang R, Cohen JY, Osakada F, Kobak D, Machens CK, Callaway EM, 
Uchida N, Watabe-Uchida M (2016) Distributed and mixed information in monosynaptic inputs to dopamine neurons. Neuron 91:1374-1389.

Totah NK, Neves RM, Panzeri S, Logothetis NK, Eschenko O (2018) The locus coeruleus is a complex and differentiated neuromodulatory system. Neuron 99:1055-1068.e6.

Totah NK, Logothetis NK, Eschenko O (2019) Noradrenergic ensemblebased modulation of cognition over multiple timescales. Brain Res 1709:50-66.

Uematsu A, Tan BZ, Ycu EA, Cuevas JS, Koivumaa J, Junyent F, Kremer EJ, Witten IB, Deisseroth K, Johansen JP (2017) Modular organization of the brainstem noradrenaline system coordinates opposing learning states. Nat Neurosci 20:1602-1611.

Usher M, Cohen JD, Servan-Schreiber D, Rajkowski J, Aston-Jones G (1999) The role of locus coeruleus in the regulation of cognitive performance. Science 283:549-554

Valentino RJ, Page ME, Curtis AL (1991) Activation of noradrenergic locus coeruleus neurons by hemodynamic stress is due to local release of corticotropin-releasing factor. Brain Res 555:25-34.

Vazey E, Moorman D, Aston-Jones G (2018) Phasic locus coeruleus activity regulates cortical encoding of salience information. Proceedings of the National Academy of Sciences 115:E9439-E9448.

Vicq-d'Azur (1786) Traité d'anatomie et de physiologie (Band 1): Traité d'anatomie et de physiologie. Available at https://digi.ub.uni-heidelberg. de/diglit/vicqdazyr1786bd1.

Watabe-Uchida M, Zhu L, Ogawa SK, Vamanrao A, Uchida N (2012) Whole-brain mapping of direct inputs to midbrain dopamine neurons. Neuron 74:858-873.

Waterhouse BD, Woodward DJ (1980) Interaction of norepinephrine with cerebrocortical activity evoked by stimulation of somatosensory afferent pathways in the rat. Exp Neurol 67:11-34.

Waterhouse BD, Lin CS, Burne RA, Woodward DJ (1983) The distribution of neocortical projection neurons in the locus coeruleus. J Comp Neurol $217: 418-431$

Waterhouse BD, Azizi SA, Burne RA, Woodward DJ (1990) Modulation of rat cortical area 17 neuronal responses to moving visual stimuli during norepinephrine and serotonin microiontophoresis. Brain Res 514: 276-292.

Waterhouse BD, Moises HC, Woodward DJ (1998) Phasic activation of the locus coeruleus enhances responses of primary sensory cortical neurons to peripheral receptive field stimulation. Brain Res 790:33-44.

Wenzel J, Wenzel K (1812) De penitiori structura cerebri hominis et Brutorum. Tübingen, Germany. Available at http://mdz-nbn-resolving.de/ urn:nbn:de:bvb:12-bsb10315887-4.

Xiang L, Harel A, Gao H, Pickering A, Sara S, Wiener S (2019) Behavioral correlates of activity of optogenetically identified locus coeruleus noradrenergic neurons in rats performing T-maze tasks. Scientific Reports 9:1361.

Yackle K, Schwarz LA, Kam K, Sorokin JM, Huguenard JR, Feldman JL, Luo L, Krasnow MA (2017) Breathing control center neurons that promote arousal in mice. Science 355:1411-1415.

Yu AJ, Dayan P (2005) Uncertainty, neuromodulation, and attention. Neuron 46:681-692.

Zerbi V, Floriou-Servou A, Markicevic M, Vermeiren Y, Sturman O, Privitera M, von Ziegler L, Ferrari K, Weber B, Deyn P, Wenderoth N, Bohacek J (2019) Rapid reconfiguration of the functional connectome after chemogenetic locus coeruleus activation. Neuron. Advance online publication. Retrieved Jun 7, 2019. doi:10.1016/j.neuron.2019.05.034. 